\section{WILHELM vOn HAIDINGER}

W LHELM VON HAIDINGER is no more. He died after some years of failing health, though the illness to which he finally succumbed on the igth of March was a short one. Among his veteran contemporaries in the mineralogist's craft, such as Breithaupt, Karl F. Naumann, Gustav Rose, and Karl C. von Leonhard, he must have stood second on the ladder of time, the venerable Breithaupt being some four years his senior. His father, Karl Haidinger, was a mineralogist, and indeed was for several years Professor of Mining at Schemnitz. But, while Wilhelm was yet an infant, his father died at Vienna, where he had, in his latter days, filled a post in the Imperial Mint.

The young Haidinger seems in some sort to have inherited his father's taste for minerals, for he joined the class of Mohs at Gratz, where that distinguished mineralogist was giving a new impetus to the study of his science by popularising it in what was termed a natural history system of classification, and by a systematic method of discriminating the different species of minerals; and subsequently young Haidinger went to Freiberg to complete his training in Mining. Count Breunner, who came to England in 1822 , and was made a Doctor in Civil Law at Oxford, invited the young mineralogist to accompany him. He embraced the offer, and they travelled together through England, and together reached Edinhurgh, where the energetic and winning character of the young Austrian, fresh with the lore of the famous lecture-room at Gratz, at once made him friends in the Northern Athens, in the University of which capital Jameson had already made Minerals a fascinating study. Among the friends he there made was $\mathrm{Mr}$. Allan, the wealthy banker, who during the next year invited young Haidinger to make a home of his house while employed in translating the Mineralogy of Mohs into English. So after returning to Vienna, he once more, in 1823 , came to Edinburgh, and made Mr. Allan's house his head-quarters till 1827 . He áppears to have been a sort of tutor to Mr. Robert Allan, the eldest son of his generous friend ; and with him he travelled during these four years through Cornwall, and then through Norway, Sweden, Denmark, Germany, Austria, Italy, and France. It was mainly during these travels that the famous collection, afterwards the property of Mr. Robert Greg, and now in the British Museum, was formed.

During these four years he brought out his translation of Mohs' treatise, and wrote several Mineralogical pupers for the Wernerian Society and the Transac$t$ uns of the Royal Society of Edinburgh. Subseyuently he joined with his brothers in starting a orcelain manufactory at Elbogen near Carlsbad. Here e continued till 1840 , stiil, however, bringing out from lime to time memoirs on new minerals or new observations on minerals already known. The minerals Edingtonite, Stembergite, Fergusonite, Herderite, Erinite, Picrosmine, Johannite, Botryogen, and Hartite, are among those he studied and described previous to and during this period.

In 1840 he returned to his native city, Vienna, to devote l.imself more exclusively to the scientific pursuits he loved. 'Thenceforward his memoirs will be found distributed at pretty regular intervals through the Sitzungsberichte of the Vienna Academy.

Among the subjects that he worked at during the next period of his life were the optical phenomena exhibited by crystals in regard to light and colour ; more particularly those of pleiochroism. He invented, for the investigation of these, the Dichroiscope, a simple but useful little instrumerit, enabling an observer to examine and compare the different characters of the absorption exercised by a birefringent crystal on light traversing it, according as the plane of vibration of the light is parallel or perpendicular to any one of the principal sections of the crystal. The description of Hauerite, a new mineral, in fact, a manganese pyrites, was given in 1847 ; that of Kenngottite in I 857. The Haidinger brushes, a subjective phenomenon due to the eye itself, and observed in looking towards a window through a tourmaline or Nicol prism, was an illustration of the acuteness of his powers of observation. A compendious and valuable treatise on Mineralogy, brought out in 1845 , to take the place of an earlier treatise, was also, during this period of his life, continually undergoing revision for new editions; while new investigations of minerals were also appearing under his name

From the moment of the foundation of the Geological Institute for the Empire in Vienna, Haidinger was the obvious man to lead that younger generation by whose labours the new Institute was to be reared and supported. So he was its Director until some two or three years ago, when he retired from the position he had filled so well, with a Ritter's rank and a well-earned pension.

For the last twelve years of his life he had given his attention, almost to the exclusion of other scientific inquiry, to the subject of meteorites. He laboured indefatigably almost to the last in collecting specimens from any new falls of meteorites reported in any portion of the globe, that they might be added to the noble collection in the Imperial Museum; and he was always at work at the interpretation of the strange phenomena witnessed by those who have described the fall of meteorites in any language or country.

Such is a rapid review of the main features in the life of a man who seems always to have been at work whose pen was one of the readiest and busiest; whose nature was ever genial and generous; and who, at the age of seventy-seven, has finished an honourable life's work, and leaves behind him a name which Austria may cherish as that of one of her illustrious sons, and which many an Austrian and many a foreigner will remember with warm respect; while those who enjoyed nearer relations with Wilhelm von Haidinger will assuredly ever remember him with affectionate regard.

N. S. M.

\section{A TURULAR POSTAL SERVICE}

SOME large iron pipes have just been laid from the General Post Office to the Branch Office at Charing Cross, through which pipes packages of letters are blown in either direction at will, by compressed air. These tubes are to be extended from Charing Cross to the Houses of Parliament; and when the total expenses of laying pipes and of transmitting small packages through them is known by experience, very possibly the system may be extended, and letters intended for quick delivery may be sent by this method at a moderate charge.

This plan of sending messages through pipes for short distances has been employed in the City for many years in connection with the late Electric and International Telegxaph Company. Seventeen or eighteen years ago, Mr. Latimer Clark laid down tubes from the Central Office of the Company in Lothbury to the Telegraph offices in Cornhill and Mincing Lane. By means of a steam-engine which worked a great air-pump, messages enclosed in small gutta-percha carriers, each somewhat resembling a sausage in shape and size, were drawn from Cornhill and Mincing Lane to Lothbury. Additional and smaller pipes were afterwards laid down by him, so that the vacuum could be applied to the further ends of the carrying pipes, in order that messages might be sent in the opposite direction also. They were then easily transmitted to and from Cornhill, but the Mincing Lane station being two-thirds of a mile off, it was found that the friction of the air in the pipes was too great, so that carriers could be sent in one direction only, namely, from Mincing Lane to Lothbury. Some years later, when Mr. C. F. Varley became engineer to the International Telegraph 
Company, he employed compressed air to drive carriers to out-stations, and a vacuum to bring them back again. When a vacuum is employed, the carriers are driven by the ordinary atmospheric pressure only of fifteen pounds to the square inch, but when condensed air is employed, almost any pressure may be applied, so that the carriers can be driven with enormous velocity. He also substituted felt for gutta-percha carriers, since the latter were sometimes partially melted by the heat occasioned by friction, and coated the insides of the pipes with sticky matter. Further, he designed some pneumatic valves; the carriers, on arriving at the end of their journey, were made to strike against a brass button, the motion of the button set a valve to work, the valve opened the door of the chamber at the end of the pipe, the carrier then fell out, and dropped down on the table below. Thus the carriers were made to let themselves out when they arrived at the end of their journey, by which plan much hand labour on the part of assistants was saved. These improvements worked well, and are working well at the present time. Seven or eight City telegraph stations have been thus pneumat cally connected for many years.

But a further improvement in the system has been made within the past year or two by Mr. C. W. Siemens. He lays down the pipes in circuits, and has pressure in the rear, and a vacuum in front of each carrier, so that as the

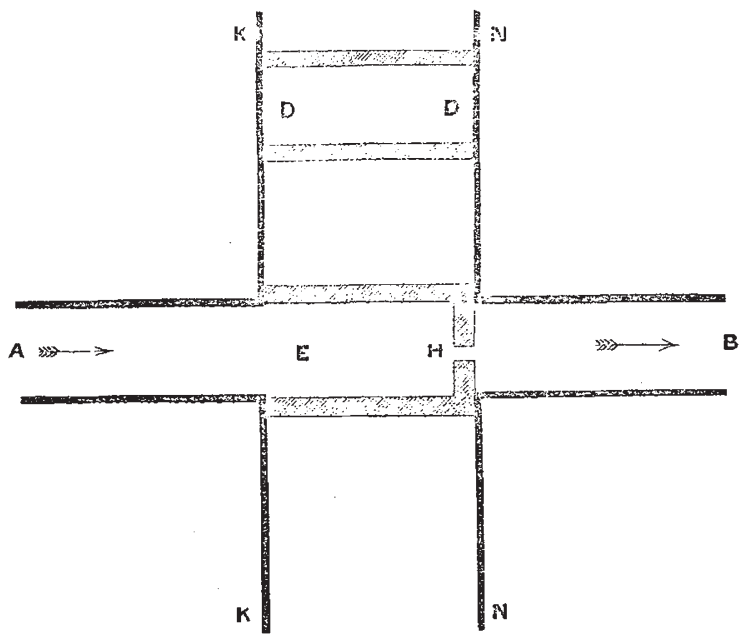

motive forces all act in one direction, there may be several carriers flying through the tubes at the same time. If these carriers were not stopped anywhere, they would all find their way back to the central station. He has invented also a "shunt," whereby any intermediate station can stop its own carrier, and pick it out of the tube without interfering with the motion of other carriers which may be flying through other parts of the circuit. Suppose the carriers to be three minutes apart in point of time, and that five stations are on the circuit, each station knows at what time its own carrier is due, so is able to take it out without interfering with other rarriers. If the carriers be not sent at regular intervals of time, the receiving station can be told when its carrier is started, by telegraph. The plan of picking out the carriers is simple, and the principle may be explained by the aid of the accompanying diagram. A B is the main tube, and the direction taken by the carriers is denoted by the arrows; $\mathrm{K} K$ and $N \mathrm{~N}$ are metal p?ates, between which the two short tubes $D$ D and $E \mathrm{H}$ slide in an air-tight manner. These two short tubes are attached to a lever joint. When the assistant does not wish to intercept a carrier, the tube $D \mathrm{D}$ is left in the place occupied by the tube $\mathrm{E} \mathrm{H}$ in the cut, and $D$ D being open at both ends, carriers pass through it without interception. Upon sliding $\mathrm{E} \mathrm{H}$ into the gap in the main tube, however, the carrier is stopped by it. It is brought to a standstill very gently, because it compresses some air in front of itself, which air issues with restricted freedom through the hole $\mathrm{H}$; thus the carrier makes for itself an air-cushion to break the violence of the blow. When the carrier is caught, the tube $D D$ is brought into the line of the main tube, after which an air-tight door in the side of $\mathrm{E} \mathrm{H}$ is opened, and the captured carrier, with its messages, is taken out.

For short distances to and from telegraph stations near the Bank and the Post Office, the pneumatic tubes are from one-and-a-half to two-and-a-half inches in diameter; they vary in diameter according to distance. But the one large Siemen's circuit at present laid in London goes from Telegraph Street to Charing Cross and back, the General Post Office and the Temple Bar Office being the intermediate stations; this pipe is three inches in internal diameter. The carriers travel at the rate of about a mile in three minutes, but the rate varies with the pressure.

It may be asked why these pneumatic tubes are useful in connection with telegraphic offices? The fact is, that there are many disadvantages in sending messages very short distances by the electric telegraph. Suppose one telegraphic wire be suspended between two stations half a mile apart, and another be suspended between two stations three hundred miles apart ; let thirty messages be received all at once for transmission over each of these two wires, it is plain that some of these messages will have to wait half an hour before their turn comes to be signalled over the wire. The public will not complain of a delay of half an hour in the delivery of a message in a town three hundred miles off, but they would make a great outcry if a message took half an hour to go half a mile by the electric telegraph. Therefore, it is the simplest and most expeditious plan for the central telegraph station in a great city to blow the messages bodily through tubes, to branch stations not far off ; the plan saves time and saves labour. Complaints published in the newspapers about delays in telegraphic messages, refer for the most part to telegrams sent from one part of London to another, and the delays are often caused by the pressure of a sudden influx of work upon particular wires. WILLIAM H. HARRISON

\section{NOTES}

WE learn that the volume containing the various observations of the recent total eclipse will be edited by the Astronomer Royal.

IT is stated that Mr. Abel, Prof. Ramsay, and Mr. Huggins, have been invited to lecture this year to the members of the British Association at the forthcoming meeting at Edinburgh.

THE meeting of the Royal Colonial Institute on Monday is likely to have a practical result. The paper read was by $\mathrm{Mr}$. Hyde Clark on the "Appointment of a Reporter on Trade Products for the Colonial Office." After an interesting -discussion the President, Lord Bury, M.P., on the part of the Council, proposed that a Committee should be named to apply to the Sccretary of State for the Colonies for such a department, and for the provision of a Colonial Museum on the same la is as the department provided at the India Office for India.

Ar the last anniversary meeting of the Chemical Society it numbered 55 $\mathrm{I}$ ordinary members and 36 foreign members. Six of the former have withdrawn from the Society, - on the other hand forty-two new members have been elected into the Society. It has lost five ordinary members by death, viz., $\mathrm{Mr}$. George Jolley, Dr. W. A. Miller, Dr. Aug. Matthiessen, Dr. J. S. Muspratt, and Mr. W. W. Rouch; and the deaths must also be recorded of two foreign members, viz., Prof. Gustav Magnus and Prof. Weltzien. The election of the president, the officers, and the other members of Council for the ensuing year 